\title{
Influence of the alginate matrix on degradation of the selected herbicides in the soil under field conditions
}

\section{Wpływ alginianowej matrycy na zanikanie wybranych herbicydów w glebie w warunkach polowych}

\author{
Małgorzata Włodarczyk*
}

\begin{abstract}
Summary
The aim of the study was to determine the influence of alginate matrix on degradation of the selected herbicides in soil. The experiment was carried out under field conditions without crop. The active substances: pendimethalin, metazachlor and clomazone immobilized in alginate matrix and in the form of commercial herbicides (respectively Panida 330 EC, Metazachlor 500 SC, Command $480 \mathrm{EC}$ ) were used in the study. The soil samples were taken for analyses 1, 3, 5, 7, 13, 21, 28, 35 days after herbicide treatment. Herbicide residues were analyzed using GC/MS (gas chromatography-mass spectrometry) method. The experimental data were fitted to the mathematical model based on first-order reaction kinetics. The times of $\mathrm{DT}_{50}$ and $\mathrm{DT}_{90}$ were calculated for all analyzed combinations of herbicides. No significant effect of the alginate matrix on the degradation of pendimethalin in the soil was observed while for metazachlor and clomazone immobilized in alginate matrix significantly longer times of $\mathrm{DT}_{50}$ and $\mathrm{DT}_{90}$ were obtained.
\end{abstract}

Key words: decay; herbicides; alginate; formulation; soil

\section{Streszczenie}

Celem pracy było określenie wpływu alginianowej matrycy na zanikanie wybranych herbicydów w glebie. Doświadczenie przeprowadzono w warunkach polowych, bez rośliny uprawnej. W badaniach wykorzystano trzy substancje czynne: pendimetalinę, metazachlor i chlomazon immobilizowane w alginianowej matrycy oraz w postaci komercyjnych herbicydów (odpowiednio Panida 330 EC, Metazachlor 500 SC, Command 480 EC). Próbki gleb pobierano po 1, 3, 5, 7, 13, 21, 28, 35 dniach po aplikacji herbicydów. Pozostałości herbicydów oznaczono metodą chromatografii gazowej z detektorem masowym (GC/MS - gas chromatography-mass spectrometry). Wyniki doświadczenia opracowano wykorzystując model matematyczny oparty na reakcji kinetyki pierwszego rzędu. Dla wszystkich analizowanych kombinacji herbicydów wyznaczono czasy $\mathrm{DT}_{50} \mathrm{i}_{\mathrm{DT}}$. Nie stwierdzono istotnego wpływu alginianowej matrycy na zanikanie pendimetaliny $w$ glebie. Dla metazachloru i chlomazonu immobilizowanych $w$ alginianowej matrycy uzyskano istotnie dłuższe czasy $\mathrm{DT}_{50}$ i DT 90 .

Słowa kluczowe: zanikanie; herbicydy; alginian; forma użytkowa; gleba

\footnotetext{
Zachodniopomorski Uniwersytet Technologiczny w Szczecinie

Wydział Kształtowania Środowiska i Rolnictwa

Zakład Chemii Ogólnej i Ekologicznej

Słowackiego 17, 71-434 Szczecin

*corresponding author: malgorzata.wlodarczyk@zut.edu.pl
} 


\section{Wstęp / Introduction}

Badania środków ochrony roślin (ś.o.r.) do celów rejestracyjnych obejmują między innymi ich wpływ na środowisko. Standardem stały się badania mające na celu określenie ich trwałości, dążące do wyznaczenia czasów zaniku $\left(\mathrm{DT}_{50}, \mathrm{DT}_{90}\right.$ ) (Guidance Document on Persistance in Soil 2000).

W środowisku glebowym, rozkład substancji czynnych wchodzących w skład preparatów herbicydowych to proces złożony obejmujący procesy chemiczne, fizyczne i biologiczne (Alister i Kogan 2006). Dominacja poszczególnych procesów i ich szybkość zależy przede wszystkim od właściwości substancji czynnej oraz warunków środowiskowych, z których istotną rolę pełnią: rodzaj gleby, zawartość węgla organicznego, $\mathrm{pH}$, wilgotność, temperatura i jej aktywności biologiczna (Van der Werf 1996; Kucharski i Sadowski 2006; Arias-Estevez i wsp. 2008; Sadowski i wsp. 2012).

Światowy rynek ś.o.r. systematycznie rośnie, a Europa jest obecnie ich największym odbiorcą. Stanowią one istotny element rolnictwa, w którym dominującą rolę pełnią herbicydy. W Polsce, zgodnie z danymi Głównego Urzędu Statystycznego, w 2014 roku, na potrzeby rolnictwa sprzedano około 65 tys. ton ś.o.r. w masie towarowej, z czego 56,1\% stanowiły herbicydy (GUS 2015).

W celu zminimalizowania negatywnego wpływu ś.o.r. na środowisko rozwijanych jest szereg technologii, których głównym celem jest uzyskanie jak największej wydajności stosowanych zabiegów, przy jak najmniejszym ich negatywnym wpływie na środowisko. Istotne znaczenie mają adiuwanty stosowane łącznie $\mathrm{z}$ herbicydami powschodowo (nalistnie), jak i przedwschodowo (doglebowo). Adiuwanty poprawiają aktywność biologiczną herbicydów, umożliwiają skuteczniejsze zwalczanie chwastów, jak również wpływają na ich trwałość i mobilność (Kucharski i Sadowski 2011). Nowe kierunki rozwoju skierowane są także w stronę badań nad formami użytkowymi, z których dominującą rolę stanowią ciecze jonowe (Pernak i wsp. 2015), czy formulacje kontrolowanego uwalniania oparte na naturalnych polimerach. Biopolimerami wykorzystywanymi jako matryce formulacji kontrolowanego uwalniania są między innymi skrobia, lignina, alginian, czy etyloceluloza. Z badań wyni$\mathrm{ka}$, że substancja czynna immobilizowana w biopolimerowej matrycy, w sposób kontrolowany uwalniana jest do środowiska glebowego i wykazuje mniejszą zdolność do przemieszczania się w profilu glebowym (Cotterill i wsp. 1996; Cao i wsp. 2005; Sopeña i wsp. 2007; Cea i wsp. 2010; Fernández-Pérez i wsp. 2011; Włodarczyk 2014).

Celem pracy było określenie wpływu alginianowej matrycy na zanikanie pendimetaliny, metazachloru i chlomazonu w glebie, w warunkach polowych.

\section{Materiały i metody / Materials and methods}

Doświadczenie polowe założono w miejscowości Zaspy Małe, gmina Białogard (N 54,032123; E 16,163071), w 2011 roku, w okresie od maja do czerwca, na polu wcześniej nieużytkowanym rolniczo, gdzie niestosowane były żadne zabiegi agrochemiczne. W badaniach wykorzystano herbicydy: Panida 330 EC w dawce 3,0 1/ha (990 g s.a./ha), Metazachlor $500 \mathrm{SC}$ w dawce 2,5 1/ha (1250 g s.a./ha) i Command 480 EC w dawce 0,25 1/ha (120 g s.a./ha) oraz substancje czynne: metazachlor, pendimetalinę i chlomazon immobilizowane w alginianowej matrycy, których zastosowana dawka odpowiadała dawce polowej komercyjnego preparatu. Formulacje oparte na alginianowej matrycy otrzymano w Centrum Bioimmobilizacji i Innowacyjnych Materiałów Zachodniopomorskiego Uniwersytetu Technologicznego w Szczecinie (Włodarczyk i wsp. 2010). Podstawowym kryterium przy wyborze substancji czynnych do badań, była ich rozpuszczalność w wodzie (pendimetalina 0,33 $\mathrm{mg} / \mathrm{l}$, metazachlor $450 \mathrm{mg} / \mathrm{l}$, chlomazon $1102 \mathrm{mg} / \mathrm{l}$ ) (Praczyk i Skrzypczak 2004). Wykorzystany w badaniach metazachlor (stopień czystości 98,6\%) został udostępniony przez firmę Feinchemie Schwebda GmbH, Niemcy, natomiast pendimetalinę (stopień czystości 97,1\%) i chlomazon (stopień czystości 99,9\%) udostępniły Zakłady Chemiczne Organika-Sarzyna Polska. Herbicydy: Panida 330 EC, Metazachlor 500 SC i Command 480 EC otrzymano z Instytutu Ochrony Roślin - Państwowego Instytutu Badawczego w Poznaniu.

Poletka doświadczalne założono na glebie lekkiej należącej do $\mathrm{V}$ klasy bonitacyjnej kompleksu żytniego dobrego. Gleba charakteryzowała się składem granulometrycznym piasku gliniastego, o zawartości węgla organicznego na poziomie $0,85 \%$ i $\mathrm{pH}$ kwaśnym $\left(\mathrm{pH}_{\mathrm{H}_{2} \mathrm{O}}=5,56\right.$; $\mathrm{pH}_{\mathrm{KCl}}=4,28$ ). Dla każdej analizowanej kombinacji wytyczono 3 obiekty o rozmiarach $1,5 \mathrm{~m} \times 2,0 \mathrm{~m}$ oddzielonych pasami izolacyjnymi o szerokości $1,5 \mathrm{~m}$ (w sumie 21 poletek doświadczalnych, w tym trzy obiekty kontrolne). Doświadczenie prowadzono bez rośliny uprawnej. Po aplikacji herbicydów, próbki gleby pobierano w 1, 3, 5, 7, $13,21,28,35$ dniu doświadczenia $\mathrm{z}$ warstwy powierzchniowej 0-5 cm (Namieśnik i wsp. 1995). Dla każdej kombinacji pobierano około $1,5 \mathrm{~kg}$ gleby (po 0,5 kg z każdego powtórzenia), którą dokładnie wymieszano i przechowywano w opisanych plastikowych torbach, w temperaturze $-20^{\circ} \mathrm{C}$. W każdym dniu poboru oznaczano aktualną wilgotność gleby, która wahała się w granicach od 0,76 do 10,40\%. Przed ekstrakcją badanych substancji czynnych $\mathrm{z}$ gleby, próbki rozmrożono, wysuszono w temperaturze pokojowej $20 \pm 2^{\circ} \mathrm{C}$ i przesiano przez sito o średnicy oczek $1 \mathrm{~mm}$. Następnie próbki gleby (metazahlor i pendimetalina $3 \times 100 \mathrm{~g}$, chlomazon $3 \times 250 \mathrm{~g}$ ) poddano ekstrakcji acetonem. Otrzymane acetonowe ekstrakty odparowano do sucha na wyparce próżniowej, a do pozostałości dodano chloroform i osuszono bezwodnym siarczanem (VI) sodu. Po osuszeniu roztwory oczyszczono na kolumnach wypełnionych frakcjami florisilu i siarczanu (VI) sodu, odparowano do minimalnej objętości $1 \mathrm{ml}$ i poddano analizie.

Do ilościowego oznaczenia pendimetaliny, metazachloru i chlomazonu wykorzystano metodę chromatografii gazowej (Włodarczyk 2011, 2014). Zastosowano chromatograf gazowy PerkinElmer Clarus $600 \mathrm{z}$ detektorem MS i kolumnę Elite $5 \mathrm{MS}(30 \mathrm{~m} \times 0,25 \mathrm{~mm} \times 0,5 \mu \mathrm{m})$, gazem nośnym był hel. Do oznaczenia substancji czynnych zastosowano technikę jonizacji elektronami (EI). Analizy jakościowej dokonano uwzględniając czasy retencji 
(pendimetalina - 15,97 min., metazachlor - 16,07 min., chlomazon - 13,02 min.) oraz widma masowe i charakterystyczne dla herbicydów jony: pendimetalina - 162, 252, 281; metazachlor - 81, 133, 209, 277; chlomazon - 125, 204, 239. Analizę ilościową przeprowadzono metodą porównawczą opartą na krzywych wzorcowych (pendimetalina: $\mathrm{y}=354943 \cdot \mathrm{x}-44,76, \mathrm{n}=6, \mathrm{R}^{2}=0,996$; metazachlor: $\mathrm{y}=347236 \cdot \mathrm{x}-150,59, \mathrm{n}=6, \mathrm{R}^{2}=0,999$; chlomazon: $\left.\mathrm{y}=201559 \cdot \mathrm{x}-51,384, \mathrm{n}=6, \mathrm{R}^{2}=0,995\right)$. Roztwory wzorcowe substancji czynnych przygotowano w chloroformie, w zakresie stężeń od 0,0005 do $0,01 \mathrm{mg} / \mathrm{ml}$. Średni odzysk badanych substancji czynnych z gleby wyniósł: pendimetalina $-95,05 \pm 2,9 \%$, metazachlor $-94 \pm 3,5 \%$, chlomazon $-93 \pm 4,0 \%$.

Dane doświadczalne zostały opracowane przy użyciu programu statystycznego STATISTICA v. 10. W celu określenia wpływu alginianowej matrycy na zanikanie wybranych herbicydów w glebie zastosowano jednoczynnikową analizę wariancji (ANOVA). Średnie wartości stężeń $\mathrm{C}_{t}$ uzyskane dla wszystkich układów zostały porównane za pomocą testu Tuckeya (przy poziomie istotności $\mathrm{p}=0,05)$.

Wyniki doświadczenia polowego opracowano wykorzystując model matematyczny oparty na reakcji kinetyki pierwszego rzędu. Wartości stałej szybkości zaniku wyznaczono metodą estymacji nieliniowej Levenberga-Marquardta (tab. 1).

\section{Wyniki i dyskusja / Results and discussion}

Uzyskane dla wszystkich badanych substancji czynnych wyniki charakteryzują się dużą powtarzalnością. Spełniają wszelkie wymogi stawiane badaniom pozostałości ś.o.r. oraz odpowiadają procedurom zawartym w dokumencie unijnym dotyczącym walidacji metod i procedur jakości w analizie pozostałości pestycydów w żywności i paszach (Method 2011). Uzyskane eksperymentalne wartości odchylenia standardowego $\left(S_{D}\right)$ i współczynnika zmienności $(V)$ dla poszczególnych średnich będących miarą rozproszenia nie przekroczyły $20 \%$ dla danej serii pomiarów i wyniosły: $S_{D}$ od 0,97 do $14,13 \%, V$ od 0,52 do $18,41 \%$.

Zastosowany model matematyczny, oparty na reakcji kinetyki pierwszego rzędu, dobrze opisuje procesy zaniku badanych substancji herbicydowych w glebie. Potwierdzają to uzyskane dla analizowanych kombinacji wysokie wartości współczynników korelacji, których ekstremalne wartości wyniosły od 0,925 do 0,986 (tab. 1).

Na podstawie przeprowadzonych badań stwierdzono, iż alginianowa matryca w zróżnicowany sposób wpłynęła na zanikanie herbicydów w glebie. W przypadku pendimetaliny nie stwierdzono istotnego wpływu formy użytkowej na jej kinetykę zanikania w glebie, w warunkach polowych (rys. 1). W badanym okresie, niezależnie od zastosowanej formy użytkowej zanikowi uległo około 50\% zastosowanej dawki pendimetaliny. Uzyskane wartości średnich stężeń pendimetaliny dla formy EC i alginianowych kapsułek, w poszczególnych dniach doświadczenia, za wyjątkiem 28. dnia, nie różniły się istotnie. Potwierdzają to wartości stałej szybkości zaniku wynoszące: dla alginianowych kapsułek $k=0,0236 \pm 2,14 \times 10^{-3} /$ dzień, dla preparatu Panida 330 EC $k=0,0234 \pm 3,21 \times 10^{-3} /$ dzień. Równocześnie dla badanych form użytkowych pendimetaliny uzyskano identyczne czasy połowicznego zaniku $\left(\mathrm{DT}_{50}\right)$. Wyznaczony w oparciu o reakcję kinetyki pierwszego rzędu czas $\mathrm{DT}_{50}$ pendimetaliny dla alginianowych kapsułek wynoszący 29,4 dnia nie różnił się istotnie od czasu $\mathrm{DT}_{50}$ otrzymanego dla preparatu Panida 330 EC (29,6 dnia). Alginianowa matryca nie wpłynęła również na czas $90 \%$ zaniku. Wartości $\mathrm{DT}_{90}$ dla obu badanych form użytkowych pendimetaliny były zbliżone i wynosiły: 97,6 dnia (alginianowa kapsułka); 98,4 dnia (Panida $330 \mathrm{EC})$.

Odmienne zależności odnotowano dla pozostałych substancji czynnych. Forma użytkowa oparta na alginianowej matrycy nieznacznie spowolniła zanik metazachloru w glebie (rys. 2). W ciągu 35 dni doświadczenia zanikowi uległo od 85\% (alginianowe kapsułki) do 90\% (Metazachlor $500 \mathrm{SC}$ ) zastosowanej dawki metazachloru. Istotne różnice w stężeniach substancji czynnej między alginianowymi kapsułkami a preparatem Metazachlor 500 SC były

Tabela 1. Parametry zaniku herbicydów w glebie, w warunkach polowych

Table 1. Parameters of degradation of herbicides in soil under field conditions

\begin{tabular}{|c|c|c|c|c|c|}
\hline \multirow[t]{2}{*}{$\begin{array}{l}\text { Kombinacja } \\
\text { Combination }\end{array}$} & $\begin{array}{l}\text { Stała szybkości } \\
\text { zaniku } \\
\text { Degradation rate } \\
\text { constant } \\
k \\
\end{array}$ & $\begin{array}{c}\text { Błąd stałej } \\
\text { szybkości zaniku } \\
\text { Degradation rate } \\
\text { constant error } \\
k\end{array}$ & $\begin{array}{l}\text { Czas } \\
\text { Time } \\
\mathrm{TD}_{50}\end{array}$ & $\begin{array}{l}\text { Czas } \\
\text { Time } \\
\text { TD }_{90}\end{array}$ & \multirow[t]{2}{*}{$\begin{array}{c}\text { Współczynnik } \\
\text { korelacji } \\
\text { Correlation } \\
\text { coefficient } \\
\mathrm{R}^{2}\end{array}$} \\
\hline & \multicolumn{2}{|c|}{ dzien $^{-1}-$ day $^{-1}$} & \multicolumn{2}{|c|}{ dzien $^{-1}-$ day $^{-1}$} & \\
\hline Panida 330 EC & 0,0234 & $3,21 \times 10^{-3}$ & 29,6 & 98,4 & 0,970 \\
\hline $\begin{array}{l}\text { Pendimethalin - alginianowe } \\
\text { kapsułki - alginate capsules }\end{array}$ & 0,0236 & $2,14 \times 10^{-3}$ & 29,4 & 97,6 & 0,925 \\
\hline Metazachlor 500 SC & 0,1053 & $1,26 \times 10^{-2}$ & 6,6 & 21,9 & 0,986 \\
\hline $\begin{array}{l}\text { Metazachlor - alginianowe } \\
\text { kapsułki - alginate capsules }\end{array}$ & 0,0830 & $1,45 \times 10^{-2}$ & 8,4 & 27,7 & 0,964 \\
\hline Command $480 \mathrm{EC}$ & 0,0589 & $2,79 \times 10^{-3}$ & 11,8 & 39,1 & 0,983 \\
\hline $\begin{array}{l}\text { Clomazone - alginianowe } \\
\text { kapsułki - alginate capsules }\end{array}$ & 0,0256 & $6,29 \times 10^{-3}$ & 27,1 & 89,9 & 0,973 \\
\hline
\end{tabular}




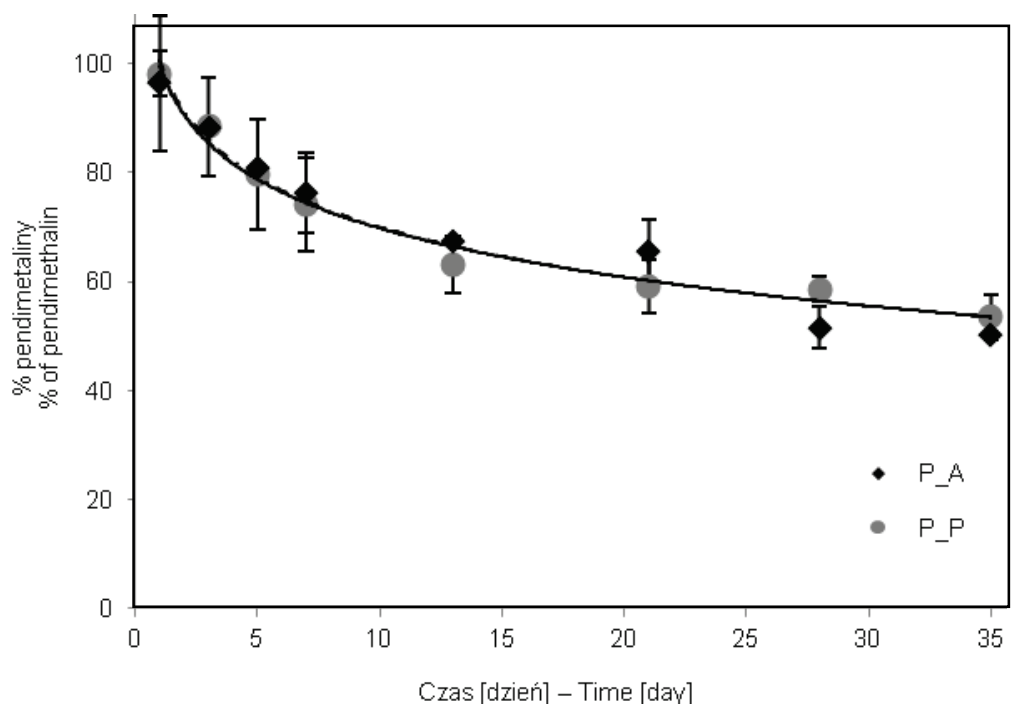

Rys. 1. Zanikanie pendimetaliny w glebie, warunki polowe

Fig. 1. Pendimethalin degradation in soil, field conditions

P_A - pendimetalina immobilizowana w alginianowej matrycy; P_P - preparat Panida 330 EC

P_A - pendimethalin immobilized in alaginate matrix; P_P - product Panida 330 EC

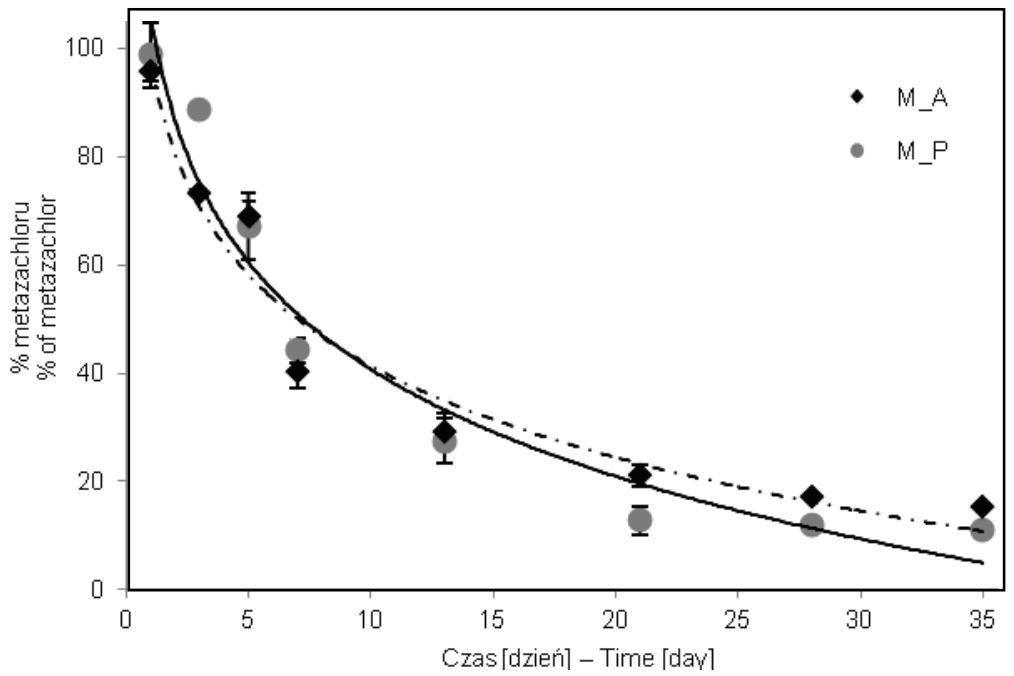

Rys. 2. Zanikanie metazachloru w glebie, warunki polowe

Fig. 2. Metazachlor degradation in soil, field conditions

M_A - metazachlor immobilizowany w alginianowej matrycy; M_P - preparat Metazachlor 500 SC

M_A - metazachlor immobilized in alaginate matrix; M_P - product Metazachlor 500 SC

istotne w 3, 21, 28 i 35 dniu doświadczenia. Różnice te wpłynęły istotnie na wartości czasów zaniku $\mathrm{DT}_{50} \mathrm{i} \mathrm{DT}_{90}$. Wyliczony czas $\mathrm{DT}_{50}$ dla metazachloru immobilizowanego w alginianowej matrycy wyniósł 8,4 dnia i jest o ponad $25 \%$ dłuższy od czasu DT $_{50}$ metazachloru uzyskanego dla preparatu Metazachlor 500 SC. Także dla alginianowej matrycy uzyskano dłuższy czas $\mathrm{DT}_{90}$ metazachloru (tab. 1).

Największy wpływ alginianowej matrycy na proces zaniku badanych herbicydów odnotowano w przypadku chlomazonu. Po 35 dniach od zastosowania herbicydu, w próbkach gleby stwierdzono pozostałości chlomazonu na poziomie: $40 \%$ stężenia początkowego - alginianowe kapsułki, 20\% stężenia początkowego - preparat Com- mand 480 EC. Dla chlomazonu wyodrębnić można dwa etapy w procesie jego zaniku w glebie (rys. 3). Pierwszy etap trwający od 1. do 7. dnia doświadczenia, w którym różnice w ilości oznaczonej substancji czynnej w glebie, pomiędzy formami użytkowymi były statystycznie nieistotne oraz drugi etap trwający od 13. do 35. dnia, w którym stwierdzono wyraźne spowolnienie zaniku chlomazonu immobilizowanego $\mathrm{w}$ alginianowej matrycy. Potwierdzają to wyznaczone dla obu porównywanych form użytkowych chlomazonu stałe $k$ : alginianowa kapsułka $0,0256 \pm 6,29 \times 10^{-3} /$ dzień, Commad 480 EC 0,0589 $\pm 2,79 \times$ $10^{-3}$ /dzień. Różnice w szybkości zaniku chlomazonu dały odzwierciedlenie także $\mathrm{w}$ wartościach $\mathrm{DT}_{50}$ i $\mathrm{DT}_{90}$. 


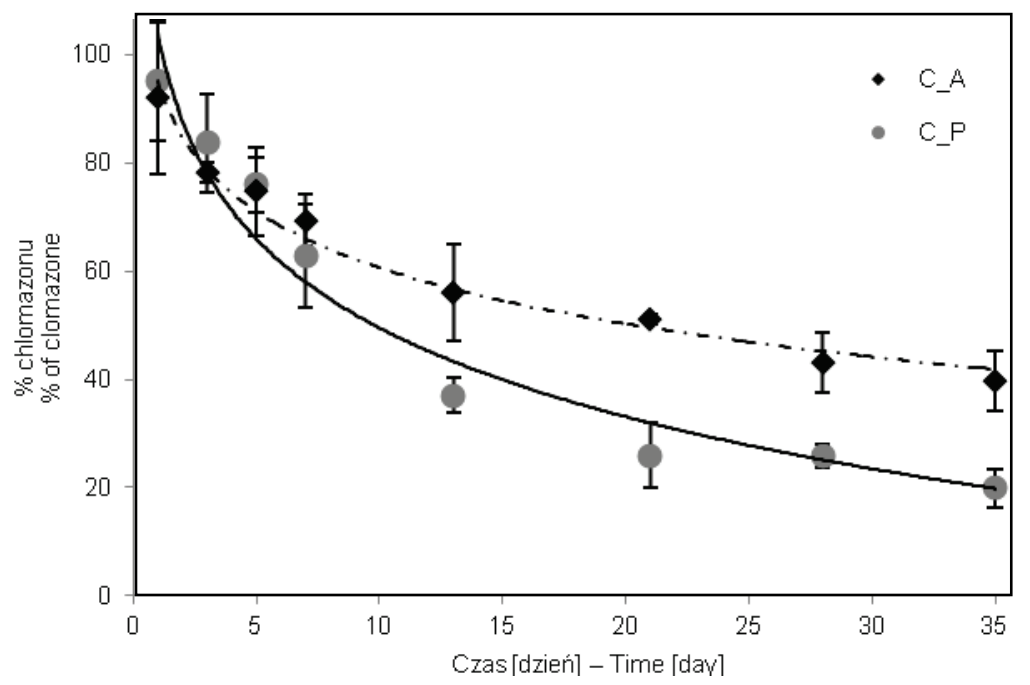

Rys. 3. Zanikanie chlomazonu w glebie, warunki polowe

Fig. 3. Clomazone degradation in soil, field conditions

C_A - chlomazon immobilizowany w alginianowej matrycy; C_P - preparat Command 480 EC

C_A - clomazone immobilized in alaginate matrix; $\mathrm{C}_{-} \mathrm{P}$ - product Command $480 \mathrm{EC}$

W przypadku alginianowych kapsułek chlomazonu, czas połowicznego zaniku wyniósł 11,8 dnia i jest o około 15 dni dłuższy od czasu uzyskanego dla formy użytkowej EC. Również czas $\mathrm{DT}_{90}$ potwierdza hamujący wpływ alginianowej matrycy na zanik chlomazonu w glebie w warunkach polowych. Dla formy alginianowej wyniósł on 89,9 dnia, natomiast dla emulsji wodnej (Command 480 EC) 39, 1 dnia.

Alternatywą dla standardowych form użytkowych stały się formulacje oparte na technologii kontrolowanego uwalniania (CR). Badania formulacjami CR skupiają się głównie nad parametrami związanymi z kinetyką uwalniania substancji czynnych, czy ich mobilnością w środowisku glebowym (Flores-Céspedes i wsp. 2007; Fernández-Pérez i wsp. 2011). Z badań własnych wynika także, że technologia CR oparta na biodegradowalnych polimerach może wpływać na zanikanie herbicydów w glebie. Wpływ ten zależy przede wszystkim od właściwości fizykochemicznych immobilizowanych substancji, w szczególności od rozpuszczalności w wodzie oraz od samej technologii otrzymywania formulacji. Immobilizacja substancji czynnej w polimerowej matrycy przyczynia się do zmniejszenia jej ilości w roztworze glebowym, gdzie jest bezpośrednio poddawana działaniu czynników odpowiedzialnych za biologiczną, fizyczną i chemiczną degradację.

Dla metazachloru i chlomazonu immobilizowanych w alginianowej matrycy otrzymano istotnie dłuższe czasy $\mathrm{DT}_{50} \mathrm{i} \mathrm{DT}_{90}$, natomiast w przypadku pendimetaliny, takich zmian nie stwierdzono. Podobne zależności otrzymał El-Nahhal (2003) badając wpływ formy użytkowej na trwałość alachloru w glebie, w warunkach szklarniowych i polowych. Herbicyd alachlor zastosowany w postaci organicznej formulacji opartej na glinie wykazał istotną trwałość w glebie, mniejszą zdolność do mobilności i większą aktywność w porównaniu do komercyjnej formulacji EC.

\section{Wnioski / Conclusions}

1. Wpływ alginianowej matrycy na zanikanie badanych herbicydów w warunkach polowych jest zróżnicowany, zależny od właściwości fizykochemicznych immobilizowanych substancji czynnych.

2. Stwierdzono istotny wpływ alginianowej matrycy na proces zaniku metazachlroru i chlomazonu w glebie. Dla obu herbicydów skonfekcjonowanych w postaci alginianowych kapsułek otrzymano istotnie dłuższe czasy zaniku. Dla metazachloru czasy $\mathrm{DT}_{50}$ i DT $_{90}$ były dłuższe ponad $25 \%$, natomiast dla chlomazonu ponad $100 \%$ w porównaniu do form SC i EC.

3. Nie stwierdzono istotnego wpływu alginianowej matrycy na zanikanie pendimetaliny $\mathrm{w}$ glebie. Czasy $\mathrm{DT}_{50}$ i $\mathrm{DT}_{90}$ dla obu form były zbliżone.

Praca wykonana w ramach projektu badawczego nr NN305151433, finansowanego przez Ministerstwo Nauki i Szkolnictwa Wyższego.

Wykorzystany w badaniach Chromatograf Clarus 600 firmy PerkinElmer zakupiony został z projektu nr OR16-61535-OR16000021/07, w ramach działania 4.6 „Działania innowacyjne i inne" Sektorowego Programu Operacyjnego „Rybołówstwo i przetwórstwo ryb 2004-2006”.

\section{Literatura / References}

Alister C., Kogan M. 2006. ERI: Environmental risk index. A simple proposal to select agrochemicals for agricultural use. Crop Protection 25 (3): 202-211. 
Arias-Estevez M., Lopez-Periago E., Martinez-Carballo E., Simal-Gandara J., Mejuto J.C., Garcia-Rio L. 2008. The mobility and degradation of pesticides in soils and the pollution of groundwater resources. Agriculture, Ecosystems and Environment 123 (4): $247-260$.

Cao Y., Huang L., Chen J., Liang J., Long S., Lu Y. 2005. Development of a controlled release formulation based on a starch matrix system. International Journal of Pharmaceutics 298: 108-116.

Cea M., Cartes P., Palma G., Mora M.L. 2010. Atrazine efficiency in an andisol as affected by clays and nanoclays in ethylcellulose controlled release formulations. Journal of Soil Science and Plant Nutrition 10 (1): 62-77.

Cotterill J.V., Wilkins R.M., Silva F.T. 1996. Controlled release of diuron from granules based on lignin matrix system. Journal of Controlled Release 40 (1): 133-142.

El-Nahhal Y. 2003. Persistence, mobility, efficacy and activity of chloroacetanilide herbicide formulation under greenhouse and field experiments. Environmental Pollution 124 (1): 33-38.

Fernández-Pérez M., Garrido-Herrera F.J., González-Pradas E. 2011. Alginate and lignin-based formulations to control pesticides leaching in a calcareous soil. Journal of Hazardous Materials 190 (1-3): 794-801.

Flores-Céspedes F., Villafranca-Sánchez M., Pérez-Garcia S., Fernández-Pérez M. 2007. Modifying sorbents in controlled release formulations to prevent herbicides pollution. Chemosphere 69: 785-794.

Guidance Document on Persistance in Soil 2000. 9188/VI/97 rev. 8, 12.07.2000. European Commission, Directorate General for Agriculture. VI B II.1. http://ec.europa.eu/food/plant/ pesticides/guidance_documents/docs/wrkdoc11_en.pdf [Accessed: 10.02.2016].

GUS 2015. Główny Urząd Statystyczny. Departament Rolnictwa. 2015. Rolnictwo w 2014 r. stat.gov.pl/download/gfx/.../p1/.../srodki_produkcji_w_rolnictwie_2014_2015.pdf [dostęp: 10.06.2016].

Kucharski M., Sadowski J. 2006 Wpływ wilgotności gleby na rozkład herbicydu - badania laboratoryjne. [Influence of soil humidity on herbicide degradation - laboratory tests]. Progress in Plant Protection/Postępy w Ochronie Roślin 46 (2): 750-753.

Kucharski M., Sadowski J. 2011. Behavior of metazachlor applied with additives in soil: Laboratory and field studies. Journal of Food, Agriculture and Environment 9 (3-4): 723-726.

Method 2011. Method validation and quality control procedures for pesticide residues analysis in food and feed. 2011. Document No. SANCO/ 12495/2011. Supersedes Document No. SANCO/10684/2009. Implemented by 01.01.2012.

Namieśnik J., Łukasiak J., Jamrógiewicz Z. 1995. Pobieranie próbek gleby. s. 88-96. W: „Pobieranie próbek środowiskowych do analizy" (J. Namieśnik, red.). PWN, Warszawa.

Pernak J., Niemczak M., Shamshina J.L., Gurau G., Głowacki G., Praczyk T., Marcinkowska K., Rogers R.D. 2015. Metsulfuron-methyl-based herbicididal ionic liquids. Journal of Agricultural and Food Chemistry 13: 3357-3366.

Praczyk T., Skrzypczak G. 2004. Herbicydy. PWRiL, Poznań, 274 ss.

Sadowski J., Kucharski M., Wujek B. 2012. Wpływ typu gleby na rozkład metazachloru. [Influence of soil type on metazachlor decay]. Progress in Plant Protection/Postępy w Ochronie Roślin 52 (2): 437-440.

Sopeña F., Cabrera A., Maqueda C., Morillo E. 2007. Ethylcellulose formulations for controlled release of the herbicide alachlor in a sandy soil. Journal of Agricultural and Food Chemistry 55 (20): 8200-8205.

Van der Werf H.M.G. 1996. Assessing the impact of pesticides on the environment. Agriculture, Ecosystems and Environment 60 (2-3): 81-96.

Włodarczyk M. 2011. Mobilność pendimetaliny immobilizowanej w hydrożelowej matrycy alginianowej w glebie. [Mobility of pendimethalin immobilized in alginate hydrogel matrix in soil]. Progress in Plant Protection/Postępy w Ochronie Roślin 51 (4): $1739-1743$

Włodarczyk M. 2014. Influence of formulation on mobility of metazachlor in soil. Environmental Monitoring and Assessment 186 (6): 3503-3509.

Włodarczyk M., Muszyńska A., Siwek H., Bartkowiak A. 2010. Optymalizacja tworzenia i charakterystyka hydrożelowych mikrokapsułek o kontrolowanym uwalnianiu wybranych herbicydów. Przemysł Chemiczny 4: 581-586. 